\title{
Abdominal Cocoon: An Unusual Cause of Subacute Intestinal Obstruction
}

\author{
Md. Yunus S. Shah • B. S. Gedam • R. Sonarkar • \\ K. S. S. Gopinath
}

Received: 12 October 2010 / Accepted: 5 June 2012 /Published online: 1 September 2012

(C) Association of Surgeons of India 2012

\begin{abstract}
We report an unusual cause of subacute intestinal obstruction in a young adolescent girl, which is a nontubercular abdominal cocoon. Barium meal follow-through revealed "cauliflower"-like appearance of small bowel. The patient underwent an exploratory laparotomy showing thick fibrous-like coverings which were encasing the small bowel loops to form an abdominal cocoon. Fibrocollagenous membrane was excised after adhesiolysis. Histopathological examination of membrane revealed fibrocollagenous membrane with hyaline deposition of nontubercular origin.
\end{abstract}

Keywords Abdominal cocoon · Sclerosing encapsulating peritonitis $\cdot$ Subacute intestinal obstruction

\section{Introduction}

The abdominal cocoon of nontubercular origin is a rare cause of subacute intestinal obstruction, characterized by

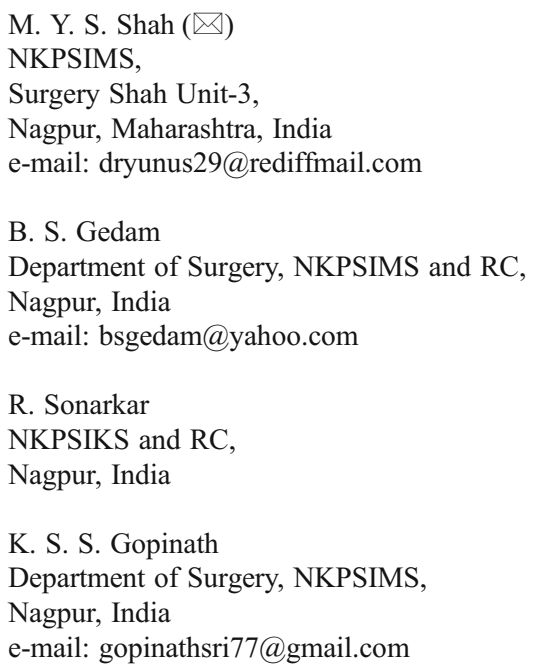

encasement of small bowel by a fibrocollagenous cocoon-like sac [1], commonly seen in young adolescent girls. The exact etiology is unknown; however, subclinical primary viral peritonitis and immunological factors have been suggested $[2,3]$. Here, we report a case of 14-year-old girl who underwent laparotomy for the abdominal cocoon.

\section{Case Report}

A 14-year-old girl presented with recurrent episodes of colicky abdominal pain and vomiting. She received antitubercular treatment for 6 months empirically. She attended menarche 8 months back. A vague mass was palpable in umbilical and hypogastric region, which was firm in consistency with indefinite margins and no mobility. Barium meal follow-through (BMFT) showed clustered small bowel loops bunched and confined to the lower abdomen, suggestive of "cauliflower sign" (Fig. 1). CT abdomen with contrast showed encapsulation of small bowel loops in a thick membrane-like sac.

An exploratory laparotomy revealed a huge globular mass occupying the lower part of the abdomen, having a thick fibrous-like covering and encasing the small bowel loops. Adhesiolysis was done and a thick whitish membrane was excised (Figs. 2 and 3). There was no evidence of abdominal tuberculosis such as mesenteric abscesses, enlarged and caseating lymph nodes, and tubercles over the bowel serosa. Postoperatively, the patient had an uneventful recovery and started tolerating oral feeds with complete relief of symptoms. She was regularly under follow-up and had gained weight. Histopathology of the membrane revealed fibrocollagenous membrane with hyaline deposition. 


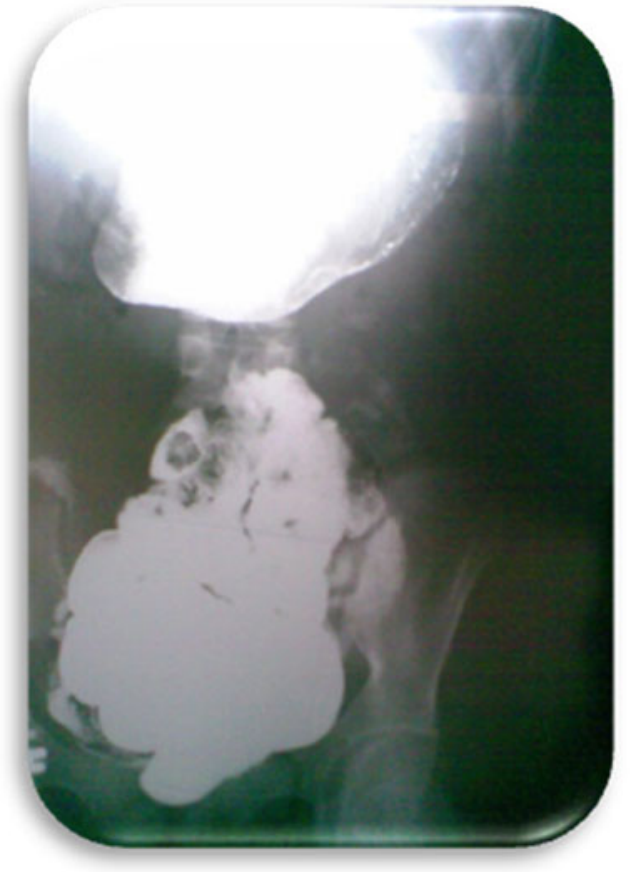

Fig. 1 Cauliflower sign on BMFT

\section{Discussion}

The abdominal cocoon or Sclerosing encapsulating peritonitis is a rare condition characterized by encasement of the small bowel by a fibrocollagenous cocoon-like sac [1]. It was first described by Foo et al. in 1978 [4]. Abdominal cocoon is classically described in young adolescent girls in tropical and sub-tropical countries. Here, the exact stimulus

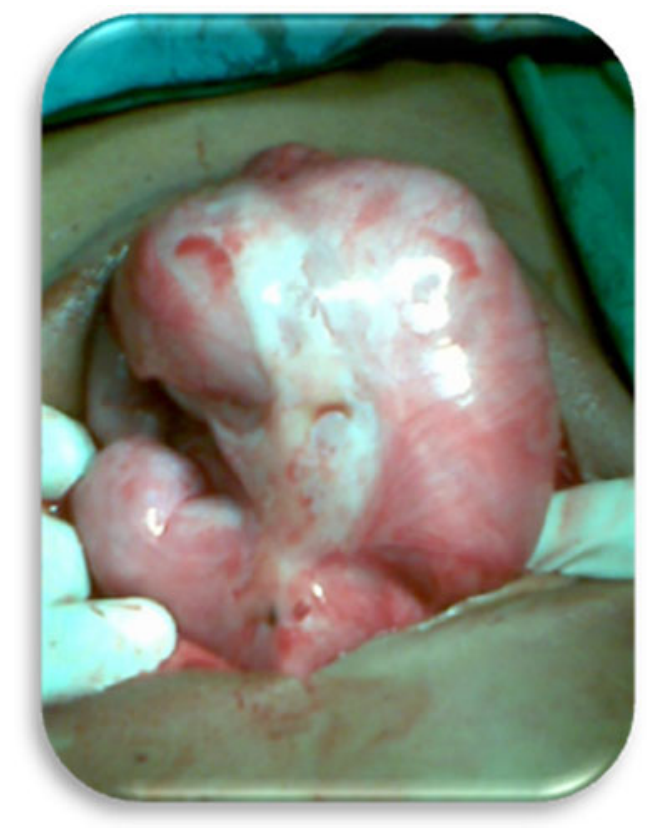

Fig. 2 Abdominal cocoon

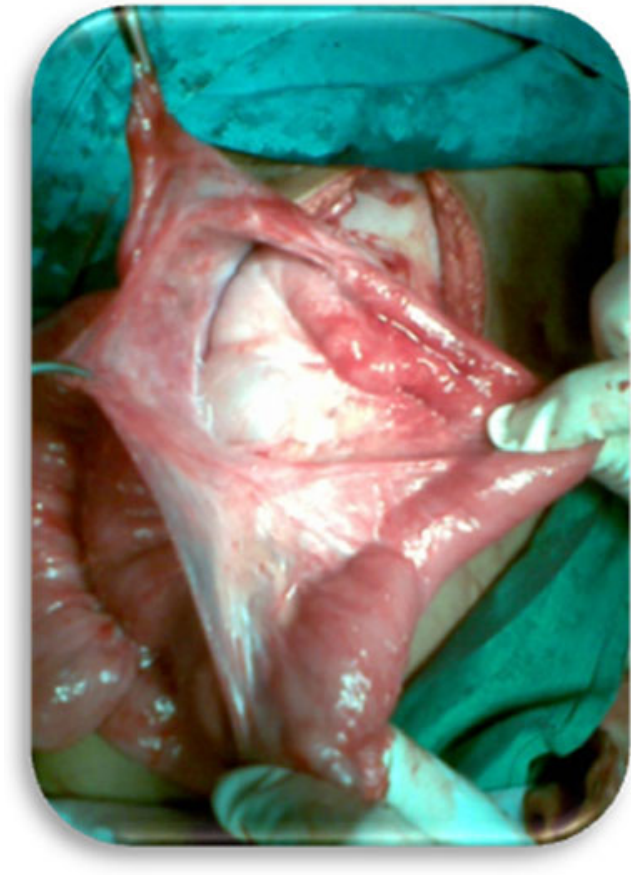

Fig. 3 Fibro-collagenous membrane separated from bowel loops

for the inflammatory reaction is not known, but some suggest it may arise due to subclinical primary viral peritonitis as an immunological reaction to gynecological infection, due to retrograde menstruation $[2,3]$. However, since this condition has also been seen to affect males, premenopausal females, and children, there seems to be little support for these theories [2, 3]. Clinically, these patients present with recurrent attacks of colicky abdominal pain, nausea, and vomiting with subacute intestinal obstruction. The abdominal mass may or may not be palpable. Sieck et al. reported "cauliflower sign" for the abdominal cocoon on barium study [5]. It is very difficult to make a preoperative diagnosis of this entity. Most of the cases are diagnosed at the time of laparotomy when the encasement of the small bowel within the sac-like cocoon is visualized. The treatment is by lysis of this covering membrane and rarely further procedure like resection is required. However, these features are probably true of cocoons arising from nontubercular etiology. Other manifestations of abdominal tuberculosis such as mesenteric abscesses, enlarged and caseating lymph nodes, and tubercles over the bowel serosa are not seen as in our case. The histopathological examination of the membranous tissue in a primary cocoon shows proliferation of fibroconnective tissue with nonspecific chronic inflammatory reaction $[6,7]$.

\section{Conclusion}

The condition of abdominal cocoon should be suspected in young adolescent girls who present with recurrent small 
bowel obstruction with no obvious cause. Early diagnosis can result in proper management and may prevent the need for bowel resection.

\section{References}

1. Bas G, Eryilmaz R, Okan I, Somay A, Sahin M (2008) Idiopathic abdominal cocoon: report of a case. Acta Chir Belg 108:266-268

2. Sahoo SP, Gangopadhyay AN, Gupta DK, Gopal SC, Sharma SP, Dash RN (1996) Abdominal cocoon in children: a report of four cases. J Pediatr Surg 31:987-988
3. Wig JD, Goenka MK, Nagi B, Vaphei K (1995) Abdominal cocoon in a male: a rare cause of intestinal obstruction. Trop Gastroenterol 16:31-33

4. Foo KT, Ng KC, Rauff A, Foong WC, Sinniah R (1978) Unusual small intestinal obstruction in adolescent girls: the abdominal cocoon. Br J Surg 65:427-430

5. Sieck JO, Cowgill R, Larkworthy W (1983) Peritoneal encapsulation and abdominal cocoon: case reports and the review of literature. Gastroenterology 84:1597-1601

6. Deeb LS, Mourad FH, El-Zein YR, Uthman SM (1998) Abdominal cocoon in a man. Preoperative diagnosis and literature review. J Clin Gastroenterol 26:148-150

7. Hur J, Kim KW, Park MS, Yu JS (2004) Abdominal cocoon: preoperative diagnostic clues from radiologic imaging with pathologic correlation. AJR Am J Roentgenol 182:639-641 